Linha D'Água (Online), São Paulo, v. 29, n. 1, p. 7-27, jun. 2016

\title{
OS PRODUTORES ÀS VOLTAS COM O TEMPO E COM A MEMÓRIA*
}

\section{LES SCRIPTEURS AUX PRISES AVEC LE TEMPS ET AVEC LA MEMOIRE}

\author{
Sylvie Plane $e^{* *}$ \\ Université Paris-Sorbonne, Paris, França
}

Resumo: Este artigo aborda as relaç̦eses entre a escrita o tempo e a memória. Examina em primeiro lugar a maneira como a escrita se inscreve na temporalidade complexa e evoca as consequências que esse fato tem sobre a atividade de linguagem do produtor de texto uma vez que este é levado a reconstruir mentalmente a imagem de seu próprio texto ao mesmo tempo em que o produz. 0 artigo ilustra esse fenômeno apoiando-se sobre uma experiência ao longo da qual os alunos foram levados a produzir várias memórias de uma narrativa. A análise das producọ̃es realizadas indica que os produtores põem em prótica de forma diversificada e evolutiva a memorização de seu próprio texto. A ocorrência de duas estratégias, uma focalizada na esquematização e outra, na memorização dos constituintes linguísticos, fica assim posta em evidência.

Palavras-chave: Escrita; Memória; Tempo; Narrativa.

Resume: Cet article s'intéresse aux rapports entre l'écriture, le temps et la mémoire. II examine en premier lieu la manière dont l'écriture s'inscrit dans une temporalité complexe et évoque les conséquences que cela a sur l'activité langagière du scripteur car celuirci est amené à reconstruire mentalement l'image de son propre texte tout en le produisant. L'article illustre ce phénomène en prenant appui sur une expérimentation au cours de laquelle des élèves ont été amenés à produire plusieurs rappels d'un récit. L'examen des productions réalisées fait apparaitre que les scripteurs mettent en œuvvre de façon diversifiée et évolutive la mémorisation de leur propre texte. La concurrence de deux stratégies, l'une focalisée sur la schématisation, l'autre sur la mémorisation des consituants linguistiques est ainsi mise en évidence.

Mots-cles: Écriture; Mémoire; Temps; Récit.

* Traduzido por Ana Lúcia Tinoco Cabral (Unicsul) - altinococabral@gmail.com

* * Professora da Université Paris-Sorbonne - Paris IV, Paris, França; sylvie.plane@wanadoo.fr 
Linha D'Água (Online), São Paulo, v. 29, n. 1, p. 7-27, jun. 2016

\section{Introdução}

A escrita é profundamente ligada à memória, e por diferentes razões. De fato, em primeiro lugar, a escrita é um sistema semiótico que permite codificar a informação, transmiti-la no tempo e no espaço. É, portanto, um meio de estabilizar essa informação, de lhe assegurar a perenidade, na forma de um texto que ficará à disposição dos leitores potenciais tanto quanto seu suporte resistir ao tempo. Essa informação, uma vez estocada no papel, na pedra ou de forma legível na tela, é, de alguma forma, uma memória externa, inerte; ela só será reativada pelos leitores que se ocuparem em procurar sentido na sequência dos caracteres grafados, interpretarem-na e apropriarem-se dela, integrando-a a seu patrimônio cultural pessoal. Mas a escrita não é apenas um sistema, ela é também uma atividade de linguagem que, como tal, solicita as capacidades mnemônicas daquele que a pratica. Como toda atividade cognitiva, ela exige que o sujeito que se dedica a ela mobilize conhecimentos já adquiridos e que ponha em funcionamento processos que requerem memória. Dito de outra forma, aos diferentes sentidos da palavra "escrita", que designa ora um sistema de codificação, ora o ato individual praticado por aquele que realiza essa codificação, correspondem aspectos da memória, diferentes eles também mas ligados entre si: no primeiro caso, a memória é encarada como um reservatório de dados que ela permite conservar, e, no segundo, ela é considerada como um mecanismo que põe em jogo operações, as quais se exercem sobre as informações registradas. É esse último aspecto que este artigo se propõe a explorar, dedicando-se às diferentes maneiras como os produtores enfrentam os problemas que apresenta o esforço de memória exigido para escrever.

Certamente, todos os produtores, qualquer que seja seu nível de competência, têm de realizar as mesmas operações para escrever. Mas eles diferem entre eles simultaneamente pelo nível de expertise - que faz com que, nos produtores proficientes, estejam automatizadas, e os recursos de que eles dispõem sejam mais abundantes e/ou mais fáceis de convocar - e pelas estratégias que eles utilizam. Para dar conta dessa questão, abordarei alguns aspectos das relações entre a escrita, o tempo e a memória. Mostrarei em particular como a escrita se inscreve numa temporalidade complexa, que concerne, ao mesmo tempo, às operações cognitivo-linguísticas utilizadas pelo produtor e à evolução do texto à medida de sua geração (PLANE, ALAMARGOT \& LEBRAVE, 2010). Apresentarei, a título de ilustração, uma experiência desenvolvida em salas de aula do ensino primário e secundário francês, com o objetivo de observar, em condições ecológicas, a escrita desses produtores singulares que são as crianças ou os adolescentes. Os resultados que serão aqui apresentados mostram que há grandes variações na maneira como 
Linha D'Água (Online), São Paulo, v. 29, n. 1, p. 7-27, jun. 2016

se opera a memorização do texto pelo produtor ao longo da produção, o que informa, em contrapartida, sobre a dinâmica da escrita.

\section{Explorar os laços entre escrita, tempo e memória}

\subsection{Tempo e memória representados pela escrita, mobilizados pela escrita}

A questão das relações entre tempo e discurso é um tema recorrente da análise linguística e da análise literária. A maioria dessas análises tomam como ponto de partida a propriedade que as línguas têm de representar o tempo por meio de sistemas que lhe são próprios e se interessam pelos usos que os sujeitos locutores ou escritores fazem dele para conferir uma medida temporal aos objetos reais ou fictícios que seus discursos representam, a narrativa sendo, naturalmente, a forma discursiva que melhor se presta a esse tipo de estudo. Mas a narrativa não se contenta em contar o tempo desdobrando uma sucessão cronológica de ações ou eventos, ela faz sobretudo com que o leitor viva o conteúdo de uma história pelo viés do interior do personagem, como o destaca Pouillon (1993, p. 168). Esse crítico distingue na verdade vários tipos de relações entre tempo e narrativa, indo do que ele chama um "simulacro", que consiste em propor ao leitor uma história cujas proporções respeitam as do tempo fictício narrado, até as formas mais sutis que passam por meio das representações do personagem que serve de intérprete no interior do qual o leitor é convidado a viver durante o tempo de sua leitura. Para ele, "o discurso interior é o verdadeiro tempo do romance", uma vez que há sincronia entre o que diz o texto e o que vive, por procuração, o leitor. Um grau suplementar é atingido quando esse tempo é, de alguma forma, mostrado pela obra literária, por pouco que esta ponha em cena o trabalho de memória operado por um personagem ou pelo narrador, como fez Proust. Indo na mesma direção, mas situando-se mais radicalmente numa perspectiva fenomenológica, Ricoeur (1985, p. 230), de sua parte, fala de experiência temporal fictícia, experiência sobre a qual ele diz que talvez não seja menos válida do que a experiência do tempo cósmico, quer dizer, do tempo efetivamente vivido pelo sujeito leitor.

Dito de outra forma, a linguagem, oral ou escrita, tem a propriedade de tornar sensível o tempo e de alimentar, assim, o trabalho da memória. Sem as palavras não sabemos do que seria nutrida nossa memória, como nos mostra, infelizmente, o caso dos pacientes que sofrem de patologias que os privam da linguagem. Mais especificamente, a escrita tem, também, a particularidade de não apenas dar a ver o tempo inventado pelo autor, quando tratar-se de ficção, ou restaurado pela sua memória, se 
Linha D'Água (Online), São Paulo, v. 29, n. 1, p. 7-27, jun. 2016

for o caso de lembranças, mas também de regular o acesso a esse tempo: o desenrolar do texto escrito dirige de alguma forma o ritmo de leitura que se fará dele.

Em resumo, a linguagem escrita exerce, pois, vários níveis de dissimulação que fazem dela controladora do tempo: I) graças à narração, ela cria um espaço temporal no qual se desenvolvem acontecimento fictícios ou memorizados e ao qual ela faz seu leitor assistir; II) graças ao acesso que ela propicia à vida interior de um personagem ou de um narrador que serve de intérprete, ela faz com que esse tempo seja vivido pelo leitor; III) graças à linearidade da materialidade linguística, ela determina o ritmo e a duração do ato de leitura por meio do qual um leitor dará vida ao texto; IV) enfim, sempre graças à linearidade, ela cria a ilusão de que o texto é gerado à medida que o leitor o descobre, como se a criação do texto fosse contemporânea à sua descoberta pelo leitor. Mas trata-se aí de uma ilusão: contrariamente à linguagem oral, a produção da linguagem escrita é anterior à sua recepção e ela se inscreve numa temporalidade singular.

Essa temporalidade da produção escrita tem fronteiras flutuantes conforme a maneira como a encaramos. De fato, é possível interessar-se apenas pelo ato de produção propriamente dito, quer dizer, por esse momento observável, que se inicia quando grafado ou digitado o primeiro signo e termina com o último signo. Mas pode-se também levar em consideração as raízes desse ato de escrita, que se inicia com a sedimentação de experiências linguísticas constituindo um já presente que estimulará, e em seguida nutrirá, o projeto de escrita. Pode-se igualmente levar em conta o fato de que o texto, mesmo que ele seja considerado como acabado, e até mesmo remetido a seu destinatário, pode permanecer presente na mente de seu autor, de alguma forma. Mas essa temporalidade estendida, que começa com premissas do projeto de escrita e se estende enquanto a obra produzida não tenha sido apagada da memória do produtor, é efêmera e inacessível ao pesquisador. Focalizarei, portanto, sobretudo a parte observável do ato de escrita, sem, no entanto, deixar de fazer algumas incursões a aspectos relativos ao que precede a textualização propriamente dita.

\subsection{Pontos de partida opostos para descrever as relações entre o tempo, a memória e a escrita}

Desde há várias décadas, a questão da temporalidade da escrita - entendida aqui como ato gráfico e escritural - suscita muito interesse. Ela é tratada principalmente em duas áreas de pesquisa, o da psicologia cognitiva, de um lado, e o da crítica genética, de outro. Essas duas áreas são complementares, uma vez que uma se interessa pelo processo enquanto a outra toma como ponto de partida os textos. 
Linha D'Água (Online), São Paulo, v. 29, n. 1, p. 7-27, jun. 2016

No campo da psicologia cognitiva, o ângulo de ataque é o da modelização dos processos redacionais. De fato, desde o modelo pioneiro de Hayes e Flower (1980) que, defendendo a ideia da recursividade dos processos redacionais, introduziu uma ruptura em relação aos modelos retóricos baseados em etapas que dominavam até então, o objetivo foi dali para frente afinar as formalizações da atividade escritural apoiando-se em experiências desenvolvidas num quadro muito controlado (cf. exame de questões em Heurley 2006). Entretanto, se a maioria dos modelos formais concordam com o fato de que a escrita requer vários níveis de tratamento (prelinguístico, linguístico, motor, metacognitivo), as questões de temporalidade ainda estão pouco esclarecidas e não são objeto de consenso. Ora, seu esclarecimento é um objetivo para esses modelos na medida em que sua pertinência depende de sua capacidade de estabelecer o encadeamento dos processos cognitivos e suas interações, como mostraram Piolat e Roussey (1992). Mais precisamente, as divergências dizem respeito aos funcionamentos mnemônicos, com duas concepções que se opõem, aquela advinda do modelo capacitário da memória de trabalho (MdT) desenvolvido por Baddeley (1986) e aplicado à redação por Mc Kutchen (1998) e a concepção da memória de trabalho de longo prazo (LTWM) desenvolvido especialmente por Kellogg. O modelo de Kellogg (1999) tem a especificidade de dedicar-se a dar conta da administração dos sub-processos, e em particular do registro viso-espacial que estoca provisoriamente as informações e está, portanto, implicado na produção de escrita.

A evolução dos modelos de produção está fortemente ligada à das tecnologias de coleta de dados em tempo real que se atribuíram a finalidade de fornecer observáveis que permitam ao pesquisador reconstituir, por inferência, as operações cognitivas realizadas pelos produtores. Passou-se do simples registro cronométrico da alternância entre atividade gráfica e pausas, tal como o faziam Matsuhashi (1981) ou Fortier e Préfontaine (1994), a dispositivos mais sofisticados de acompanhamento da digitação no computador, especialmente com Inputlog, desenvolvido por Leijten e van Waes (2006), e Scriptlog, utilizado por Stromqvist et al. (2006), numa perspectiva desenvolvimentista; ou sistemas de eye tracking, que permitem estabelecer correlações entre os movimentos oculares e os gestos gráficos, como Eye and pen, desenvolvido por Alamargot e Chenet.

No campo da crítica genética, contrariamente à perspectiva que guia as pesquisas em psicologia cognitiva, não se trata de forma alguma de conduzir a uma modelização, mas, ao contrário, caracterizar um objeto de estudo sempre singular. O objetivo é, na realidade, reconstituir a gênese de um texto particular, como fizeram Lumbroso (2004) ou Hamon (2009, p. 15) a partir dos cadernos de Zola, ou definir o modo de escrita de um autor fundando-se na observação de regularidades 
Linha D'Água (Online), São Paulo, v. 29, n. 1, p. 7-27, jun. 2016

nas operações de escrita, como propõe Pétillon (2005). De fato, como mostrou Grésillon (1994), a cronologia da elaboração de textos literários ou especulativos, únicos por essência, possivelmente estabelecida a partir das informações fornecidas pelos dossiês preparatórios constituídos pelos autores e da identificação das operações de escrita. Mas, tal como o diz Hay (1979), contrariamente à filosofia clássica, o estabelecimento dessa cronologia não está submetida a uma concepção teleológica da escrita que compreendesse que as intervenções sucessivas do produtor sobre seu texto constituam necessariamente melhorias. As análises visam sobretudo a dar conta das estratégias de escrita, conscientes ou não, reveladas pela sucessão das operações e pelas estratificações enunciativas que informam sobre o diálogo virtual entre o texto e seu autor.

\subsection{Uma dinâmica que resiste à observação.}

Entre essas duas abordagens foram estabelecidas ligações. O diálogo permitiu que fossem instituídas metodologias que recorriam aos dois campos, em particular aqueles que recaem sobre o tempo real, e que ferramentas de análise circulem de uma comunidade científica à outra, como comprovam as publicações interdisciplinares coordenadas por Petillon \& Ganier (2006) e por Fenoglio \& Chanquoy (2007). As convergências foram facilitadas pela construção de um quadro comum elaborado por Plane, Olive e Alamargot (2010) que definiu a atividade de produção de escrita como o tratamento de um sistema de coerções de duas ordens, linguísticas e psicológicas, antagonistas, não hierarquizáveis entre elas, e oferecendo graus de liberdade diferentes. A complexidade das coerções linguísticas e a variabilidade do grau de liberdade que elas deixam para o produtor tornam impossível o recurso a uma resolução pré-programada. De fato, como mostrou Nolke (1999), por conta da diversidade dos componentes que entram em jogo nos fenômenos linguísticos e da especificidade de suas regras internas, não existe algoritmo de resolução capaz de permitir automatizar as escolhas linguísticas da produção verbal. A mesma complexidade é encontrada no que concerne às coerções psicológicas, pois sua gestão solicita a memória de trabalho, que deve, simultaneamente, operar tratamentos de ordem linguística e estocar informação; ora a capacidade dessa memória é limitada, o que pesa sobre o desenvolvimento dos processos implicados na redação conforme mostraram especialmente Fayol (1999, p. 49) e Fayol et Largy (1992) por ocasião de protocolos de dupla função. As pausas no desenrolar da escrita e os erros (erros de digitação ou erros gráficos, erros ortográficos, lapsus calami, etc.) são todos indícios que assinalam que a atenção do produtor foi mobilizada sobre um 
Linha D'Água (Online), São Paulo, v. 29, n. 1, p. 7-27, jun. 2016

aspecto da produção escrita em detrimento de outro em razão da multiplicidade de exigências a gerenciar simultaneamente.

O tempo, que é uma das dimensões da memória, não é, portanto, simplesmente um elemento do contexto da produção de escrita, mas um fator que desempenha um papel em dois níveis e inscreve a escrita numa dinâmica complexa. Toda produção de texto põe em jogo simultaneamente dois processos, a atividade linguístico-cognitiva do produtor e a geração de um texto, porém esses dois processos são imperfeitamente síncronos mas interdependentes. $\mathrm{O}$ fato de que o desenvolvimento do texto dependa da atividade do produtor não tem nenhuma necessidade de ser demostrado, mas algumas palavras são necessárias para mostrar que a relação de dependência é recíproca. Acontece realmente que as tomadas de decisão do produtor são em parte determinadas pelo substrato sobre o qual elas se exercem, isto é, pelo texto, mas o estado desse substrato se altera continuamente: é, inicialmente, um projeto, quer dizer, uma imagem vaga e virtual, sem contorno; em seguida, graças à atividade gráfica do produtor, ele toma uma forma material, adquire consistência, densidade linguística e significação. $\mathrm{O}$ trabalho cognitivo do produtor se apoia, portanto, sobre um objeto evolutivo, que é o texto em curso de escrita. Ora, a evolução desse objeto altera os graus de liberdade oferecidos ao produtor: a parte do texto já escrita consistiu de alguma forma uma instrução, como no exercício escolar da continuação do texto no qual as palavras iniciais impõem suas regras no texto que virá, mas essas palavras iniciais se incrementam constantemente e fazem, portanto, evoluir as instruções de escrita.

A tarefa para o produtor torna-se complexa logo que o texto atinge certa extensão porque ele não fica mais imediatamente disponível na memória de trabalho e precisa tornar-se objeto de uma recuperação na memória de longo termo e/ou de uma consulta direta. Vários indícios informam sobre os acasos da recuperação na memória. Assim acontece de serem cometidos alguns erros que atestam que o produtor se apoiou, por exemplo, para gerenciar questões de coerência ou de concordâncias gramaticais, em segmentos de texto que tinham sido grafados mas que foram posteriormente suprimidos, particularmente por apagamento na escrita digital. Assim se explicam alguns erros de concordância que têm a ver com uma relação sintagmática entre o segmento linguístico que se adiciona e um segmento eliminado, mas conservado na memória pelo produtor, como se este se apoiasse sobre um membro fantasma. $\mathrm{O}$ recurso à consulta visual do texto cuja escrita está em desenvolvimento é atestado por experimentos que utilizam dispositivos 
Linha D'Água (Online), São Paulo, v. 29, n. 1, p. 7-27, jun. 2016

de acompanhamento dos movimentos oculares ${ }^{1}$. Alamargot, Plane et al. (2009) mostraram inclusive que as modalidades da recuperação visual no curso da escrita sobre o texto já produzido diferia em função da expertise.

Mais exatamente, à medida da produção do texto, o autor é levado a realizar dois grandes tipos de tratamento mnemônicos que recaem sobre seu próprio texto a fim de poder referir-se a ele: I) como mostraram Le Bigot, Passerault, Olive (2011), o produtor estabelece marcações topológicas a fim de conservar a lembrança da disposição espacial de seu texto, o que lhe permite reportar-se a ele visualmente durante a escrita; II) ele elabora e registra uma imagem do conteúdo semântico de propriedades linguísticas do texto. Em outras palavras, ele não memoriza o texto igualzinho, mas realiza sobre seu texto um conjunto de operações que se assemelham àquelas postas em uso na atividade de leitura e na de produção verbal oral, como vou explicar.

\subsection{A produção verbal escrita entre leitura e produção verbal oral}

Desde Johnson-Laird (1983, p. 126), que introduziu a noção de modelo mental, e Kintsch e van Dijk (cf resenha em Denhière \& Baudet 1987), que definiram os princípios da análise proposicional na origem da base textual, ficou admitido de forma geral que, quando da tarefa de leitura/compreensão, a atividade cognitiva do leitor se orienta não em direção à memorização fiel de cada segmento linguístico, mas na direção de uma representação do conteúdo. O tratamento em recepção dos materiais linguísticos está na verdade a serviço da elaboração de uma estrutura não linearizada no seio da qual as informações fornecidas pelo texto em leitura são interligadas. Le $\mathrm{Ny}$ (1989, p. 192) ressalta igualmente que, em razão dos fenômenos de inferência que intervêm ao longo da leitura, a fonte de uma informação pode não ser memorizada pelo leitor. É por isso que, no fim da leitura de uma narrativa, o leitor pode reformular a sua diegese e citar de memória fórmulas extraídas do texto, mas ele não pode restituir o texto palavra a palavra. Nessa particularidade, a leitura-compreensão se opõe à prática de leitura para decorar, atividade cujo objetivo primeiro é não compreender, mas memorizar in extenso o texto.

Fenômenos comparáveis intervêm nos momentos da produção oral, tendo com particularidade o fato de que o locutor deve fazer um esforço de memorização cujo objeto são seus próprios propósitos. Assim, o que Barbéris e Maurer (1998)

Software Eye and Pen@, desenvolvido por Denis Alamargot e David Chesnet.

PLANE, S. Os produtores às voltas com o tempo e com a memória 
denominam "ratage" ${ }^{2}$ e todas as partes medíocres do oral sinalizam não apenas a complexidade da tarefa de enunciação, mas também a dificuldade da memorização de um texto oral pelo seu autor. Isso se constata facilmente em situações usuais de comunicação: os limites da memória de trabalho impedem ao locutor de reiterar in extenso o enunciado que ele mesmo acabou de produzir por menos longo que seja esse enunciado, o que explica, por outro lado, particularidades dos enunciados orais.

As situações de escrita, de leitura e de produção verbal oral têm, portanto, as três em comum o fato de exigir que o sujeito realize, ao longo da atividade, operações de armazenamento de informação. Mas, no caso da leitura, os elementos a serem memorizados são provenientes do tratamento de um texto produzido por um agente externo, o autor, enquanto, no caso da escrita e da produção oral, os elementos a serem memorizados são procedentes do discurso produzido pelo próprio sujeito. Em contrapartida, leitura e produção de escrita oferecem ambas a possibilidade de se reportar visualmente aos dados fonte e, logo, consultá-los.

A produção de escrita apresenta as similitudes e as diferenças com a leitura e a produção oral que acabamos de evocar, mas comporta igualmente especificidades. De fato, o texto a partir do qual se opera a memorização foi redigido pelo produtor e é, portanto, composto de elementos linguísticos que o produtor já tinha ele próprio memorizado anteriormente sob formas mais ou menos bem-sucedidas. Tal texto, foi em parte estabilizado, mesmo que de maneira reversível, pelo ato gráfico. Entretanto, assim como assinalamos anteriormente neste trabalho, o texto não é memorizado tal qual in extenso pelo seu autor, como comprova o fato de que o autor consulta constantemente seu texto ao longo da escrita. Propomos chamar de ressemantização o conjunto de operações de recodificação de seu próprio texto por um autor intervindo no momento da memorização desse texto (ao longo da atividade de escrita ou posteriormente) porque essas operações convocam uma reorganização das ligações e das estruturas semânticas.

Para esclarecer os processos de ressemantização, e sobretudo para localizar as variantes interindividuais na sua textualização, um experimento foi realizado com a finalidade de observar as transformações operadas por ocasião de reescritas.

2 A palavra ratage diz respeito ao fato de não atingir o seu objetivo.

PLANE, S. Os produtores às voltas com o tempo e com a memória 
Linha D'Água (Online), São Paulo, v. 29, n. 1, p. 7-27, jun. 2016

\section{Um dispositivo para observar a maneira como os produtores lidam com a escrita}

\subsection{Coerções metodológicas}

O experimento sobre o qual vou apresentar alguns elementos foi desenvolvido numa perspectiva didática. Trata-se na realidade de caracterizar os modos de escrita que são empregados por crianças em idade escolar a fim de auxiliar à instauração de situações de ensino apropriadas. Para a organização desse experimento, três premissas foram levadas em conta:

- Respeito às situações ecológicas. Isso impõe que o experimento se desenvolva no contexto habitual das aulas trazendo a menor perturbação possível e com a colaboração dos professores. Essas condições impedem, portanto, o uso de materiais sofisticados, como os dispositivos de controle ocular, e conduzem a propor atividades próximas daquelas com as quais os alunos estão acostumados. Stricto sensu, trata-se, logo, de um protocolo quase experimental, pois, contrariamente às situações de laboratório, os experimentos em sala de aula põem em jogo conjuntos de parâmetros - condições materiais, contexto pedagógico, etc. - que é impossível de unificar.

- Coleta de elementos permitindo comparações estreitas entre os modos de ressemantização empregados pelos diferentes produtores. Para isso, era preciso evitar que essas operações interviessem em substratos heterogêneos, o que teria sido o caso se a instrução de escrita tivesse dado aos produtores a liberdade de inventar todas as partes do texto que eles iam escrever. Para eliminar o risco de disparidade, a opção foi impor como ponto de partida para os produtores participantes do experimento o mesmo substrato inicial, a saber, um conto; e, para dispor de um ponto de referência fácil de se explorar, o mesmo conto foi apresentado sob duas formas diferentes entre si, mas com um ponto comum, o modo de discurso reportado.

- Neutralização das dificuldades de decifração: se no desenrolar da primeira etapa tivesse sido pedido aos alunos de ler um texto, poder-se-ia temer que os leitores pouco hábeis encontrassem dificuldades de compreensão por causa de seu domínio insuficientes do código. Por esse motivo, o pondo de partida do experimento foi a comunicação oral de um texto para os alunos em vez de dar para que eles o lessem. 
Linha D'Água (Online), São Paulo, v. 29, n. 1, p. 7-27, jun. 2016

\subsection{0 texto fonte}

O suporte para o experimento tem como origem um conto que Raponda Walker ${ }^{3}$ recolheu e traduziu do omyéné ${ }^{4}$ para o francês. Esse conto, As três astúcias da gazela, tem a vantagem de apresentar semelhanças com os contos com os quais os alunos escolarizados na França estão habituados, com uma tríade que facilita a sua memorização. Ele participa da mesma linha que fábulas ou narrativas lidas em sala de aula ou estudadas na Fundamental II, como o Roman de Renart, que põe em cena um animal esperto que engana outro mais forte, mas mais ingênuo. No caso, tratase de uma gazela que engana um leopardo, e isso por três vezes. Mas essa narrativa tem também a vantagem inversa de não fazer parte do repertório cultural clássico dos alunos, pois ela se situa num universo exótico: trata-se de um vinho de palma, de uma bebida chamada itoutou, de antílopes, de redes para transportar as presas. Adaptamos o texto de maneira a minimizar as dificuldades lexicais e elaboramos duas versões desse texto, uma na qual os propósitos dos personagens são contados no discurso direto e outra na qual o discurso direto foi evitado. Coletamos assim material para examinar especificamente o tratamento do discurso reportado (PLANE, RONDELLI \& VÉNÉRIN, 2013) mas também, de maneira mais ampla, para identificar os procedimentos utilizados pelos produtores para lidar com os diversos problemas de memorização postos pela atividade de escrita prescrita.

\subsection{Desenvolvimento Déroulement}

O dispositivo comporta quatro fases:

a) Escuta pelos alunos do texto do conto intitulado: "As três astúcias da Gazela". O texto, que tinha sido gravado por um locutor orientado a não marcar efeito de entonação, foi passado para os alunos. A transmissão por meio de uma gravação permitiu evitar disparidades introduzidas pela forma como cada professor teria interpretado o texto se ele tivesse que fazer ele próprio a leitura oral.

Duração da gravação: texto A : 5’30"; texto B : 5'28”

Número de palavras gráficas: texto A : 150 ; texto B : 989

3 Contes gabonais coletados por André Raponda-Walker, edição de 1996, publicado por Présenca africaine.

4 O omyéné é uma língua banto falada no Gabão.

PLANE, S. Os produtores às voltas com o tempo e com a memória 
Linha D'Água (Online), São Paulo, v. 29, n. 1, p. 7-27, jun. 2016

b) Restituição por escrito do texto ouvido, imediatamente após a audição. Os alunos receberam a orientação de escutarem atentamente o conto gravado, de não tomarem nenhuma nota e de se esforçarem para memorizar porque lhes seria pedido de escrever o texto logo após a escuta. Eles foram avisados que, na análise que faríamos de seus textos, não levaríamos em conta a ortografia, para evitar os desvios que muitos alunos fazem diante das dificuldades ortográficas em situações de tarefas de redação; o peso atribuído tradicionalmente à ortografia na atribuição de notas e a extrema complexidade do sistema ortográfico francês são tais que muitos alunos dão um jeito de evitar o risco de empregar uma palavra que eles não tenham certeza de como se escreve corretamente, mesmo que essa palavra lhes pareça a mais apropriada ao texto que eles estão redigindo.

c) Memória escrita de narrativa, uma semana após a audição. Durante a semana que se passou entre a audição e a memória escrita, os alunos não tiveram a oportunidade nem de reler o próprio texto, nem de escutar novamente a gravação.

d) Nova memória escrita da narrativa ou escrita de uma continuação, uma semana mais tarde. A escolha entre essas duas atividades foi deixada a critério dos professores para a primeira fase de pesquisa a fim de que eles se apropriassem do dispositivo. Entre a memória de narrativa e essa etapa, assim como entre a audição e a primeira memória, os estudantes não tiveram acesso a seus textos nem à gravação do conto.

\subsection{Os dados coletados}

O experimento mobilizou onze turmas, totalizando 245 alunos, indo do Curso Médio (último ano da escola primária) e das classes equivalentes às de Fundamental II até a turma de segundo ano (primeiro ano do Ensino Médio). Isso nos permitiu coletar dois corpus abundantes, o corpus A composto de produções escritas de 104 alunos que tinham como ponto de partida o texto com discurso direto, o corpus $\mathrm{B}$ das produções de 141 alunos tendo o outro texto como ponto de partida. Tratarei, neste trabalho, apenas das versões 1 produzidas imediatamente após a audição do texto fonte e das versões 2 produzidas uma semana mais tarde, a partir das lembranças. 
Linha D'Água (Online), São Paulo, v. 29, n. 1, p. 7-27, jun. 2016

\section{Breve olhar sobre as marcas de ressemantização levantadas: alguns fatos salientes atestando diversidade de procedimentos}

Os dados coletados nessa pesquisa são abundantes e se prestam a múltiplas análises. Cuidarei aqui de assinalar elementos que fornecem uma visão geral da diversidade das tendências que se opõem, tendo como perspectiva o estabelecimento de categorias que sirvam para definir estilos de escrita.

\subsection{Do texto fonte à memória da narrativa: focalização do produtor sobre a esquematização vs focalização sobre a forma linguística.}

A primeira versão dos textos colhidos é sempre de uma extensão inferior à do texto fonte. Assim, enquanto o ponto de partida era um texto de 989 palavras gráficas, a mais longa das primeiras versões produzidas pelos alunos era um texto de 543 palavras gráficas. Não é nada surpreendente que a memória de narrativa seja mais curta do que o texto fonte, pois, de um lado, os limites das capacidades de memória fazem com que seja impossível conservar na sua completude um texto longo, de outro lado, a tarefa de compreensão que se impõe implicitamente aos ouvintes/leitores de uma narrativa estabelece uma seleção de informações fornecidas pelo texto visando à sua integração. Mas é interessante notar que duas tendências opostas se manifestam - com todas as variações possíveis entre esses dois polos de um lado os textos nos quais a redução procede majoritariamente de fórmulas extraídas do texto fonte, as quais o produtor combina organiza, e no oposto, textos que privilegiam a reformulação sintética. $\mathrm{Ou}$, para retomar a tipologia que Grize (1992) aplicava aos resumos, para alguns produtores, a memorização do texto se assemelha ao "resumo-amostra", enquanto, para outros, ela se aproxima da síntese, privilegiando as operações de esquematização e a reformulação.

As primeiras palavras são particularmente esclarecedoras a esse respeito. Assim, pode-se comparar ${ }^{5}$ :

(1) A Gazela, que tinha tomado emprestado do Leopardo uma grande soma em dinheiro, atrasava todos os dias o momento de reembolsar esse dinheiro. Cansado de esperar, um dia, o Leorpardo decidiu cobrar da Gazela o seu dinheiro (Texte source B)

5 A ortografia dos textos dos alunos foi corrigida.

PLANE, S. Os produtores às voltas com o tempo e com a memória 
Linha D'Água (Online), São Paulo, v. 29, n. 1, p. 7-27, jun. 2016

(2) A gazela tinha tomado emprestado uma grande soma de dinheiro do leopardo. O leopardo cansado de esperar decidiu ir buscar o dinheiro. (Jé 6v1) ${ }^{6}$

(3) Um leopardo dá dinheiro para uma gazela. Mas ele deseja recuperar esse dinheiro. (Mo 2v1)

Enquanto o léxico de (2) foi extraído do texto fonte, com exceção de "buscar" que substitui "recuperar", o texto (3) mantém do texto fonte apenas o nome dos objetos e dos atores. A reorganização da informação em (3) se manifesta por uma mudança de tematização que coloca de imediato o leopardo em posição de agente - e, portanto, de actante do ponto de vista diegético - fazendo dele o sujeito do verbo "dar" por uma construção em espelho da fórmula do texto fonte que comportava, por sua vez, a expressão verbal "tomar emprestado".

A escolha entre os tipos de procedimento de condensação pode ser interpretada como ligada a auto-comandas implícitas que os produtores se dariam, uns visando à fidelidade às "palavras do texto" e os outros a uma restituição/interpretação do conteúdo. Os dados coletados não permitem atribuir essas tendências ao ensino recebido (não há homogeneidade numa mesma classe) nem à idade dos produtores, mas muito mais a estilos que lhes são próprios.

\subsection{De uma versão a outra: deterioração vs construção}

O fato de que o texto proveniente da prova de memória seja de uma extensão inferior à do texto fonte não é, portanto, uma surpresa. Da mesma forma, prevíamos que o texto proveniente da memória diferida no tempo fosse mais curto que aquele proveniente da memória imediata pois, durante o intervalo de uma semana que separou os dois momentos, a lembrança do texto fonte deve ter-se deteriorado. $\mathrm{E}$ constatamos efetivamente que muitas das versões 2 eram mais curtas que a primeira versão escrita pelo mesmo aluno.

Mas é mais surpreendente de ver que, em quase um quarto dos casos, o inverso aconteceu: as segundas versões são mais longas e mais precisas que as primeiras. Três hipóteses são consideradas para explicar esse crescimento das quais as duas últimas são compatíveis entre elas:

6 As referências dos textos dos alunos estão anotadas assim: duas primeiras letras do nome, número indicando a turma, número da versão ; assim, "Jé6v 1" significa: texto de Jérémie, aluno de $6^{\circ}$, primeira versão. 
Linha D'Água (Online), São Paulo, v. 29, n. 1, p. 7-27, jun. 2016

I) Durante o intervalo que separa o dois momentos, os alunos teriam conversado entre eles evocando a narrativa ouvida. Encontra-se aí um obstáculo difícil de driblar, mas que constitui uma ameaça séria, pois os conteúdos das aulas sem objetivo em temos de nota alimentam pouco as conversas privadas entre os alunos.

II) Quando da primeira prova de memória, o esforço cognitivo exigido pela textualização não teria permitido alocar recursos suficientes para evocar elementos estocados na memória de longo prazo. Em contrapartida, quando da segunda prova de memória, a tarefa de textualização seria mais fácil, uma vez que ela já tinha sido efetuada uma primeira vez e fixada pela sua transcrição gráfica, o que oferece ao produtor mais disponibilidade para mobilizar lembranças da narrativa ouvida ${ }^{7}$. A diferença de fluidez gráfica entre as duas versões é uma indicação em favor dessa interpretação. Assim, a primeira versão de Guillaume, aluno da segunda série, (primeiro ano do Ensino Médio), comporta 48 palavras +9 palavras rabiscadas +1 esboço de palavra, enquanto a versão oriunda da memória diferida, de uma grafia com maior domínio, comporta 231 palavras e apenas duas rasuras.

III) Entre os dois momentos, o texto continua a trabalhar seu autor, para retomar a palavra de Lejeune (2005) que expõe como "a escrita ultrapassa o momento em que se escreve". Fenoglio (2007) fala da ruminação do texto, Bucheton (1996) se seu "adensamento", um e outro assinalando que os traços gráficos observáveis (incluindo-se aqueles que figuram nos pré-textos) ensinam apenas de forma imperfeita sobre os contornos temporais da produção textual. Dito de outra forma, a produção textual propriamente dita é apenas um fragmento recortado pelo artefato que constitui a escrituração numa atividade de linguagem contínua que começa antes mesmo do ato de escrita, com o que Eco (1992) chama de as intentiones auctoris e se prolonga pela repetição incansável - assumida ou sofrida - do texto produzido. Os elementos que se seguirão constituem argumentos em favor dessa hipótese.

7 Eu agradeço nessa ocasião John Hayes que teve a gentileza de me indicar os trabalhos de Beth Littleton que, com outros métodos, confrontam essa hipótese in Littleton, Elizabeth, 1998, «Emerging Cognitive Skills for Writing: Sensitivity to Audience Presence in Five-Through NineYear-Olds' Speech» Cognition and Instruction, Vol 16, Issue 4, 399-430. 
Linha D'Água (Online), São Paulo, v. 29, n. 1, p. 7-27, jun. 2016

\subsection{Do texto fonte às duas versões: desenvolvimento dos scripts e jogo da intertextualidade}

Se é verdade que se nota com frequência uma perda de substância de uma versão a outra, constata-se também, como já afirmei anteriormente, o inverso. $\mathrm{O}$ acréscimo de informações suplementares foi levantado nos diferentes estados do dispositivo: o texto proveniente da memória imediata pode conter, em algumas passagens, mais informações que o texto fonte; e a segunda versão pode, por sua vez, ser mais explícita ou precisa que a primeira.

A comparação dos diferentes estados de texto (texto fonte/ versão 1 / versão 2) mostra que esse enriquecimento se deve principalmente a dois procedimentos às vezes difíceis de dissociar: o desenvolvimento de um script e a mobilização de referências intertextuais.

Os scripts - ou, para le $\mathrm{Ny}$ (1989, p. 130), os cenários - foram sobretudo estudados nos trabalhos que tratam de leitura. Desde há muito tempo foi mostrado que a memorização de scripts culturalmente partilhados, quer dizer, sequências de ações ordenadas no tempo procedendo da decomposição analítica de situações usuais, é um instrumento da compreensão. Esses scripts, que fazem parte da enciclopédia pessoal do leitor, são convocados especialmente para resolver, por inferência, problemas de referência e suprir, como o afirma Eco $(1985$, p. 29), as lacunas dessa máquina preguiçosa que é o texto. Do lado da produção de escrita, eles foram estudados através dos estereótipos que mobilizam os aprendizes produtores, especialmente por Kervyn e Dufays (2003).

Exemplos como o que segue levam a pensar que os scripts intervêm não apenas na leitura e no inventio quando da concepção de um texto, mas igualmente no processo de memorização de seu próprio texto pelo produtor.

O texto fonte se apresenta assim:

(4) Ele chegou na casa da Gazela, quando ela estava ainda na cama. A Gazela, apesar de incomodada com a súbita chegada do Leopardo, o acolheu bem (...)

A primeira versão do aluno retoma uma parte do léxico inicial:

(5) Ele chegou na casa da Gazela numa hora da manhã bem cedo, mas ela o acolheu, apesar de tudo, de forma bastante calorosa (Ev 6v1)

A forma é mais condensada mas comporta, no entanto, a adição de uma precisão de horário (numa hora da manhã bem cedo) oriunda da interpretação 
Linha D'Água (Online), São Paulo, v. 29, n. 1, p. 7-27, jun. 2016

da situação narrada: como a gazela estava na cama, pode-se deduzir que a ação se situava de manhã cedo.

A segunda versão produzida pelo mesmo aluno não faz mais menção às circunstâncias temporais, mas desenvolve um script:

(6) Um dia, ele decidiu ir cobrar dela, ele chegou na porta e bateu. A gazela abriu a porta. (Ev 6v2)

É provável que esse script da introdução dentro de uma residência seja proveniente da leitura de contos e faça parte do repertório dos jovens leitores, pois encontramos, nos textos de um outro aluno, que frequenta outra escola e, portanto, sem contato com o primeiro, um desenvolvimento análogo:

(7) A gazela o viu chegar e fez como se não o tivesse visto. O Leopardo bateu na porta. (Ra6v1)

A presença desses scripts ou fragmentos de scripts é um elemento que corrobora os resultados das pesquisas desenvolvidas numa perspectiva bakhtiniana que mostraram a importância da caracterização genética na produção de textos por jovens produtores, e especialmente os trabalhos de Lafourcade (2008). No nosso corpus, o gênero do conto tinha sido nitidamente identificado como prova a abundância dos comentários metadiscursivos ("é a história de") e das marcas caracterizando o conto ("era uma vez") levantadas nos contos produzidos. Mas se já se tem como conhecido que, por ocasião do inventio, o texto extrai uma parte de seus traços nos recursos genéricos de que o produtor dispõe, as constatações feitas por ocasião deste experimento conduzem a acrescentar que esse fenômeno se prolonga quando o autor memoriza o seu texto. De alguma forma, no momento dessa memorização do texto, que intervém ao longo de toda sua produção, tal texto se incorpora progressivamente ao patrimônio interno do produtor e extrai dele de volta novos traços, o que que faz com que, no momento em que o produtor procura rememorar o que ele escreveu, ele pode convocar, por contaminação, elementos provenientes de outras produções de linguagem próximas.

\section{Pistas de trabalho para concluir}

A partir de um mesmo plano feito de uma coleção de operações interdependentes, existem múltiplas maneiras de escrever, quer dizer, de realizar essas operações, de as orquestrar, de conceder mais ou menos peso ou atenção a uma ou outra 
entre elas. Essas maneiras de escrever podem ser circunstanciais: a carga afetiva ligada à produção de um texto que envolva intimamente o produtor, o esforço de conceptualização que exige a redação de um texto que trate de um assunto particularmente abstrato ou, ao contrário, o rabisco rápido de um breve texto sem objetivo mobilizam de forma diferente as capacidades linguísticas do produtor. Mas existem também maneiras de fazer que caracterizam os produtores, especialmente a maneira como se efetua a memorização de seu texto à medida da sua escrita e mais precisamente a maneira como se opera a ressemantização ao longo da escrita. Por ocasião de um experimento que tinha um objeto completamente diferente - tratava-se de comparar a produção de escrita no computador e a produção de escrita manuscrita em crianças de escola elementar, foi observado que, numa fase de reescrita, alguns produtores se comportavam, relativamente à sua própria produção, como se fosse um texto que lhes seria estranho e não conseguiam mais aderir ao sistema diegético que eles próprios tinham estabelecido (Plane 2003). Esse descompasso entre a intenção primitiva expressa na primeira versão e a que motivava a segunda versão aparecia como uma espécie descomprometimento por parte do produtor que não conseguia mais ser o leitor cooperativo de seu próprio texto. Sem dúvida, a hipótese da ressemantização ao longo da escrita pode dar conta desse fenômeno. É evidente que existem muitas variáveis na seleção e na execução dos procedimentos de ressemantização. Algumas devem ter ligação com a idade dos produtores especialmente em razão dos papeis que desempenham a fluência da escrita e a composição dos recursos de linguagem estocados sob a forma de esquemas e daquilo que Paveau $(2006,2007)$ chama de pré-discurso. Mas esses fatores não são suficientes para dar conta da diversidade dos procedimentos e falta identificar outras variáveis; o objetivo não é categorizar os produtores, mas, ao contrário, colocar em evidência funcionamentos idiossincrásicos que testemunham diferentes formas de ser autor de seu texto.

\section{Referências}

ALAMARGOT, Denis; PLANE, Sylvie, LAMBERT, Eric; CHESNET, David, 2010, «Using Eye and Pen Movements to Trace the Development of Writing Expertise: Case Studies of a Seventh, Ninth and Twelfth Grader, Graduate Student, and Professional Writer», Reading and Writing, 23(7), 853-888.

BADDELEY, Alan, 1986, Working Memory, Londres, Oxford University Press. 
Linha D'Água (Online), São Paulo, v. 29, n. 1, p. 7-27, jun. 2016

BARBERIS, Jeanne-Marie; MAURER, Bruno, 1998, «Sur le «ratage» en discours oral», L'information grammaticale $77,43-47$.

BOURDIN, Béatrice, 1999, «Mémoire de travail et production langagière: comparaison de l'oral et de l'écrit chez les adultes et les enfants», L'année psychologique, vol 99, n 1,123-148.

BUCHETON, Dominique, 1996, «Lépaississement du texte par la réécriture», in J. David \& et S. Plane (dir.), L'apprentissage de l'écriture de l'école au collège, Paris, PUF, 159-184.

DENHIERE, Guy; BAUDET, Serge, 1987, «Traitement du texte», in J.-A Rondal \& J.-P. Thibault (éd.) Problèmes de psycholinguistique, Bruxelles, Pierre Mardaga éditeur, 43-85.

ECO, Umberto, 1992, Les limites de l'interprétation, Paris, Grasset et Fasquelle.

ECO, Umberto, 1979, trad. 1985, Lector in fabula, Paris, Stock.

FENOGLIO, Irène, 2007, «Du texte avant le texte. Formes génétiques et marques énonciatives de pré-visions textualisantes», Langue française, 155, 8-34.

FENOGLIO, Irène; CHANQUOY, Lucile, 2007, «Avant-Propos. La notion d'avant-texte: point de rencontre pour une compréhension de l'écriture en acte», Langue française, 155, 3-7.

FORTIER, G.; PREFONTAINE Clémence, 1994, «Pauses, relecture et processus d'écriture», Revue des sciences de l'éducation, vol. 20, n. 2, 203-220.

GRESILLON, Almuth, 1994, Éléments de critique génétique. Lire les manuscrits modernes. Paris, Puf.

FAYOL, Michel, 1999, Des idées au texte. Psychologie cognitive de la production verbale orale et écrite, Paris, Puf.

FAYOL, Michel; LARGY, Pierre, 1992, «Une approche cognitive fonctionnelle de l'orthographe grammaticale. Les erreurs d'accord sujet-verbe chez l'enfant et chez l'adulte», Langages, 95, 80-98.

GRIZE, Jean-Blaise, 1992, «Résumer, mais pourquoi?», in M. Charolles \& A. Petitjean, L'activité résumante, Metz, Centre d'Analyse Syntaxique de l'Université de Metz, 53-61.

HAMON, Philippe, 2009, Le signe et la consigne. Essai sur la genèse de l’euvre en régime naturaliste, Genève, Droz.

HAY, Louis, 1979 «La critique génétique. Origine et perspectives», in L. Hay (dir.) Essais de Critique Génétique, Paris, Flammarion, 227-236. 
Linha D'Água (Online), São Paulo, v. 29, n. 1, p. 7-27, jun. 2016

HAYES, John; FLOWER, Linda, 1980, «Identifying the organization of writing processes», in L.W. Gregg \& E.R. Steinberg (dir.) Cognitive Processes in Writing. Hillsdales, Laurence Erlbaum, 3-30.

HEURLEY, Laurent, 2006, «La révision de texte: l'approche de la psychologie cognitive» Langages, 164,10-25.

HAMON, Philippe, 2009, Le signe et la consigne. Essai sur la genèse de l'cuvre en régime naturaliste, Genève: Droz.

JOHNSON-LAIRD, Philip, 1983, Mental Models: toward a cognitive Science of Language, Cambridge, Cambridge University Press.

KERVYN, Bernadette; DUFAŸS, Jean-Louis, 2003, «Quels usages du stéréotype dans l'écriture au secondaire?», Pratiques 117-118, 2008-218.

LAFOURCADE, Bernadette, 2008, Traitement des contraintes formelles liées au genre et au médium de production par des scripteurs novices, Thèse de doctorat, Université Paris-Descartes.

LE NY, Jean-François, 1989, Science cognitive et comprébension du langage, Paris, Puf

LEIJTEN, Marleen; VAN WAES, Luuk, 2006, «Inputlog: New Perspectives on the Logging of On-Line Writing», Studies in Writing, 18, 73-94.

KELLOGG, Ronald, 1999, «Un modèle de la mémoire de travail dans la rédaction», in A. Piolat et A. Pelissier (éd.), La rédaction de textes. Approche cognitive, Lausanne, Delachaux et Niestlé, 103-136.

LE BIGOT, Nathalie; PASSERAULT, Jean-Michel; OLIVE, Thierry, 2011 «Implication of visuospatial and temporal information in memory for word location», Journal of Cognitive Psycho$\log y$, vol 23, issue 4, 522-530.

LEJEUNE, Philippe, 1995, Signes de vie. Le pacte autobiographique 2, Paris, Seuil.

LUMBROSO, Olivier, 2004, Zola, la plume et le compas. La construction de l'espace dans les Rougon-Macquart d'Émile Zola, Paris, Honoré Champion.

MATSUHASHI, Ann, 1981, «Pausing and planning: The tempo of written discourse production", Research in the Teaching of English, 15, 113-134.

MCKUTCHEN, Deborah, 1998, «Une théorie de la capacité pour la rédaction: la mémoire de travail dans la composition», in A. Piolat et A. Pelissier (éd.), La rédaction de textes Approche cognitive, Lausanne, Delachaux et Niestlé, 183-224.

PLANE, S. Os produtores às voltas com o tempo e com a memória 
Linha D'Água (Online), São Paulo, v. 29, n. 1, p. 7-27, jun. 2016

NOLKE, Henning, 1999, «Linguistique modulaire: principes méthodologiques et applications» in H. Nolke \& J.-M. Adam (éd.) Approches modulaires: de la langue au discours, Lausanne, Delachaux et Niestlé, 17-74.

PAVEAU, Marie-Anne, 2006, Les prédiscours. Sens, mémoire, cognition, Paris, Presses de la Sorbonne Nouvelle.

PAVEAU, Marie-Anne, 2007, «Discours et cognition: les prédiscours entre cadres internes et environnement extérieur». CORELA - Cognition, discours, contextes | Numéros thématiques

PETILLON, Sabine, 2007, «Style, critique génétique et modèles rédactionnels: perspectives linguistiques», Corpus 5, http://corpus.revues.org/index422.html.

PETILLON, Sabine ; GANIER Franck, 2006, «L'étude de la révision de texte: de la mono- à la pluri-disciplinarité», Langages, 164, 3-9.

PIOLAT, Annie, 2001, La prise de notes, Paris, Puf.

PLANE, Sylvie, 2003, «Stratégies de réécriture et gestion des contraintes d'écriture par des élèves de l'école élémentaire: ce que nous apprennent des écrits d'enfants sur l'écriture», Rivista Italiana di Psicolinguistica Applicata, anno III/1, 57-77.

PLANE, Sylvie ; OLIVE, Thierry ; ALAMARGOT Denis, 2010, «Pour une approche pluridisciplinaire de la production écrite», Langages, 177, 3-5.

PLANE, Sylvie; ALAMARGOT, Denis; LEBRAVE, Jean-Louis, 2010, «Temporalité de l'écriture et rôle du texte produit dans l'activité rédactionnelle» Langages, 177, 11-34.

PLANE, Sylvie; RONDELLI, Fabienne; VENERIN, Christine, 2013, «Variations, fidélité, infidélité: l'écriture et la réécriture de discours rapportés par de jeunes scripteurs», in C. Desoutter \& C. Mellet (dir.) Le discours rapporté: approches linguistiques et perspectives didactiques. Berne, Peter Lang, 215-232.

POUILLON, Jean, 1993, Temps et roman, Paris, Gallimard.

RICOEUR, Paul, 1985, Temps et récit. T III Le temps raconté. Paris, Gallimard.

STRÖMQVIST, Sven; HOLMQVIST, Kenneth; JOHANSSON, Victoria; KARLSSON Henrik; WENGELIN, Asa, 2006, «What keystroke-logging can reveal about writing», Studies in Writing, 18, 45-72.

Recebido: $17 / 03 / 2016$

Aprovado: 21/05/2016

PLANE, S. Os produtores às voltas com o tempo e com a memória 